\title{
New Synthesized Amino Acids-based Surfactants as Efficient Inhibitors for Corrosion of Mild Steel in Hydrochloric Acid Medium: Kinetics and Thermodynamic Approach
}

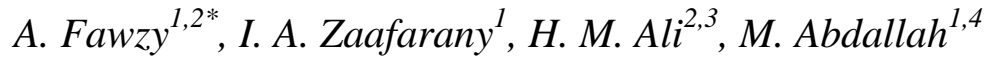 \\ ${ }^{1}$ Chemistry Department, Faculty of Applied Science, Umm Al-Qura University, Makkah, Saudi Arabia \\ ${ }^{2}$ Chemistry Department, Faculty of Science, Assiut University, Assiut, Egypt \\ ${ }^{3}$ Chemistry Department, Faculty of Science, Aljouf University, Aljouf, Saudi Arabia \\ ${ }^{4}$ Chemistry Department, Faculty of Science, Benha University, Benha, Egypt \\ *E-mail: afsaad13@yahoo.com
}

doi: $10.20964 / 2018.05 .01$

Received: 19 December 2017 / Accepted: 19 February 2018 / Published: 10 April 2018

\begin{abstract}
Three amino acids based-surfactants, namely, sodium $N$-dodecyl asparagines (AS), sodium $N$-dodecyl histidine (HS) and sodium $N$-dodecyl tryptophan (TS) were synthesized and were investigated as corrosion inhibitors for mild steel (ST-37-2) in $0.5 \mathrm{M} \mathrm{HCl}$ at $25{ }^{\circ} \mathrm{C}$. The methods employed in this work were weight-loss (WL), potentiodynamic polarization (PP) and electrochemical impedance spectroscopy (EIS). The useful surface active properties of the synthesized surfactants were also evaluated. The inhibition efficiencies were found to increase with the inhibitor concentration, while decrease with increasing the concentration of hydrochloric acid and temperature. Results obtained from the different techniques revealed that the inhibition efficiency increases in the following sequence: AS < HS < TS. The high inhibition efficiencies of the synthesized surfactants were declined in terms of strong adsorption of the surfactant molecules on mild steel surface and forming a protective film separating the steel surface from the corrosive acid medium. The adsorption operation was found to obey Langmuir isotherm. Thermodynamic and kinetic parameters were evaluated by adsorption theory and kinetic equations which support the mechanism of physical adsorption of the inhibitors. The polarization measurements showed that the tested surfactant molecules act as mixed-type inhibitors with anodic predominance. The mechanism of inhibition of mild steel corrosion was also suggested. Results obtained from all employed methods are consistent with each others.
\end{abstract}

Keywords: Amino acids-based surfactants, Mild steel, Corrosion, Inhibitors, Mechanism, Adsorption.

\section{$\underline{\text { FULL TEXT }}$}


(C) 2018 The Authors. Published by ESG (www.electrochemsci.org). This article is an open access article distributed under the terms and conditions of the Creative Commons Attribution license (http://creativecommons.org/licenses/by/4.0/). 